\title{
THE CENTRIPETAL BUILD-UP TECHNIQUE FOR RESTORATION OF INTERDENTAL CONTACT POINTS - GASE REPORT
}

\section{Bărbuceanu Lucian-Godrut', Gheorghiu Irina-Maria² , Mitran Loredana3, Mitran M.4, Iliescu Alexandru Andrei5, Perlea Paula ${ }^{6}$, Moraru Iren ${ }^{7}$}

${ }^{1}$ Private dental practice, Bucharest

2 Department of Restorative Odontotherapy, Faculty of Dental Medicine, UMF "Carol Davila" Bucharest

${ }^{3}$ Department of Otorhinolaryngology, Elias Hospital

${ }^{4}$ Department of Obstetrics and Gynecology, Faculty of Medicine, UMF "Carol Davila" Bucharest

${ }^{5}$ Department of Oral Rehabilitation, Faculty of Dental Medicine, Craiova

${ }^{6}$ Department of Endodontics, Faculty of Dental Medicine, UMF "Carol Davila” Bucharest.

${ }^{7}$ Department of Operative Dentistry, UMF Craiova

Irina-Maria Gheorghiu

Faculty of Dental Medicine, UMF "Carol Davila"

Calea Plevnei 17-23 Bucharest

email:igheorghiu@hotmail.com

\begin{abstract}
This article presents an important topic in the field of dental medicine. Reconstruction of the contact point in the lateral interdental area is obtained using a large number of type techniques, with different materials and instruments. The centripetal build up technique involves the initial restoration of the proximal absent wall, thus transforming the second-class cavity into a first-class cavity, followed by it's restoration. This technique provide a correct, appropriate contact point and an easy restoration of the occlusal morphology.
\end{abstract}

Keywords: proximal; contact points; centripetal build up techniques.

\section{Introduction}

The loss of hard tooth substance in the interdental areas, as a result of carious processes or trauma, has a high impact on the masticatory and the physiognomic function. Dental distructions in the proximal areas affects both the health and aesthetic appearance of the oral cavity and the rest of the body(1). There is also a reverse situation when the bad overall condition can affect both the teeth and the gums, but also their supporting tissues in the alveolar bone. The functions of the dento-maxillary apparatus are: mastication, swallowing, phonation, physiognomy and breathing. The entire dentition is part of the masticatory system and represents a condition of a good functioning of the entire body. The correct odontal restoration of interdental points through direct restoration (obturation) is the essential criterion in modern restorative odontotherapy for class II cavities(2). Due to the increased retention of the interdental areas, they require more attention during treatment, meaning proper rehabilitation of proximal contacts, thus a proper hygiene for the prevention of dentalmaxillofacial diseases(3).

According to a 2001-2004 study of patients who have undergone dental treatment at the Dental School of the University of Istanbul, Turkey, the prevalence of cavities on dental 
surfaces indicates that the interdental area is the most affected coronary area. The limited effect of self-cleaning, tooth brushing and saliva are the main causes for which this area is affected by $34 \%$, followed by the occlusal/incisal surface by $25 \%$ and by the oral area by $17 \%(4)$. Symptoms of dental loss in the proximal areas varies depending on the exposed dentine surface, the implication of the pulp chamber, and the damage of the interdental gingiva (dental papilla), which is the area of the gingival which fills the interdental embrasure between two adjacent teeth cervical to the contact point. When loss of hard dental tissues is present in proximal areas, discomfort created by all these complications decreases masticatory efficiency by forcing the patient to avoid mastication in the affected area, causing high abundance of dental plaque in that region, temporomandibular joint dysfunction and tooth wear in the opposite area of dental arcade(5). The interdental papilla become chronically traumatized, triggering a localized marginal chronic superficial periodontitis or periodontal pockets. Distructions of dental substance in proximal areas leads to the absence of contact points between teeth, which damage and impingement of the gingival tissues. Thus, with the interdental space created, due to the direct food impact, the dental papilla reduces its volume and changes its shape from protrusion to plateau or even concave shape(6). Inflammation of the papilla occurs as a result of chronic trauma in the presence of the microbial plaque. Lack of adequate treatment will lead to the appearance of a chronic marginal superficial periodontitis.

The configuration of the proximal cavities in the lateral areas and the conformation modalities( matricing, which is the technique when we create a temporary wall to sustain the restoration material during performing a proximal obturation) for proximal contact areas are equally important in terms of a correct restoration dental treatment(6). There are several techniques for restoring these dental areas, all aiming at a correct and optimal reconstruction of the contact points and proximal contours for the good health of oral tissues $(7,8)$. As mentioned above, interdental surfaces are retention areas, difficult to be cleaned and with increased frequency of local complications of surroundings tissues. That is why materials and methods of odontal restoration have been perfected in order to anatomically and functionally reconstruct the affected tooth, to facilitate the clinician's manoveurs and to increase the patient's comfort(9). Reproduction of proximal contact areas requires coronary conformation systems, usually called matrix. These are made up of a matrix band and a piece that supports the matrix on the tooth (matrix retainer). The matrix band is a tape that actually contributes to the restoration of missing area of the tooth, and the matrix provides it with maintenance and stabilization onto the tooth. A wedge is also mandatory in proximal restorations.

\section{Centripetal build up technique}

This is one of the most used techniques for class II (proximal cavities), almost half of dentists use this technique because it provides a firm, proper, easy to achive contact point and facile occlusal restoration(10).

The matrix retainer with a matrix and the wedge are applied at the level of the destroyed proximal area. The centripetal technique means to configure in the first place the missing proximal wall using dental materials (common resin composite), thereby transforming the secondclass cavity into a first-class cavity. Then the restoration of the tooth continues, inserting the composite to restore marginal ridge completely and occlusal anatomy. The technique offer a correct contact point, thus contributes also to proper adaptation of resin composites to gingival wall and prevent microleakage $(11,12)$.

\section{Case report}

A patient has presented to the dental practice for restoration of distal dental caries at tooth 16. (Figure 1). 


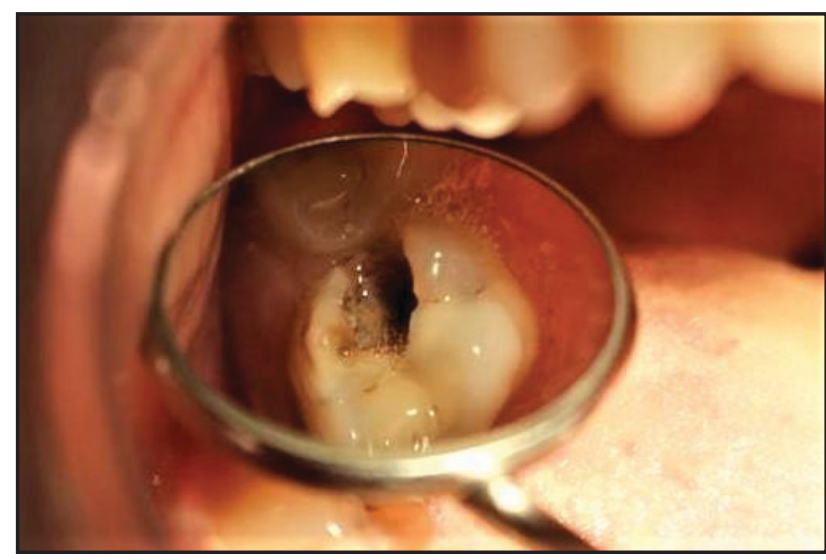

Figure 1. Carious lesion on distal surface in tooth 16.

The treatment steps were as follows: removing the dental plaque with professional brushing, choose the proper color tooth shade and dental isolation. Next, all the hard dental tissues affected by carious process have been removed and class II cavity has been obtained. ( Figure 2).

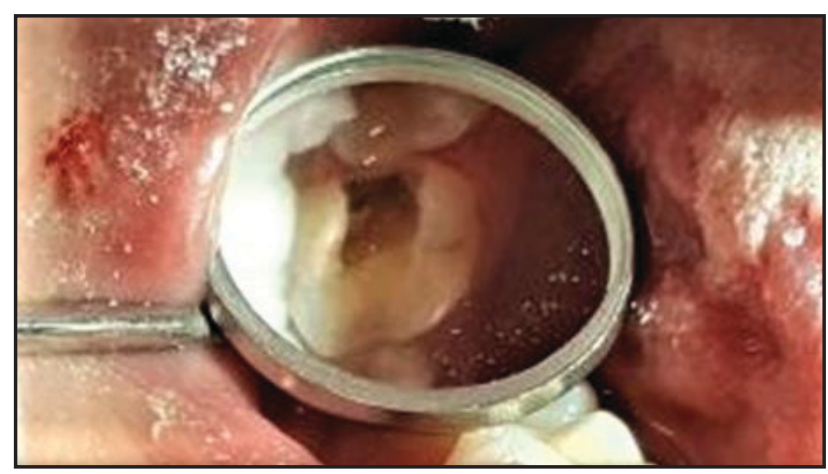

Figure 2. Class II cavity on tooth 16

For the realization of centripetal technique and insert the restorative resin composite material (Filtek TM P60, 3M ESPE), the matrix retainer (type Tofflemire) with metallic matrix have been inserted on the tooth( Figure 3).

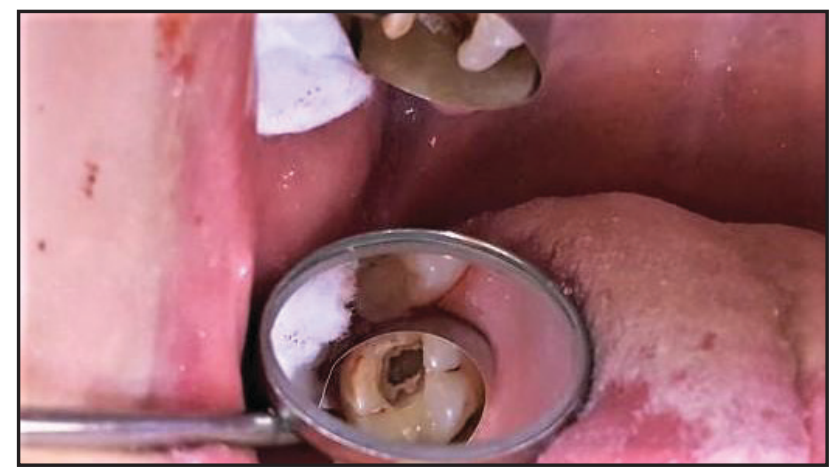

Figure 3. Tofflemire retainer inserted on tooth 16.
The next stage of treatment consisted in the achieving specific dental adhesion stages, followed by reconstruction of the distal wall of tooth 16 using resin composites ( Figure 4).

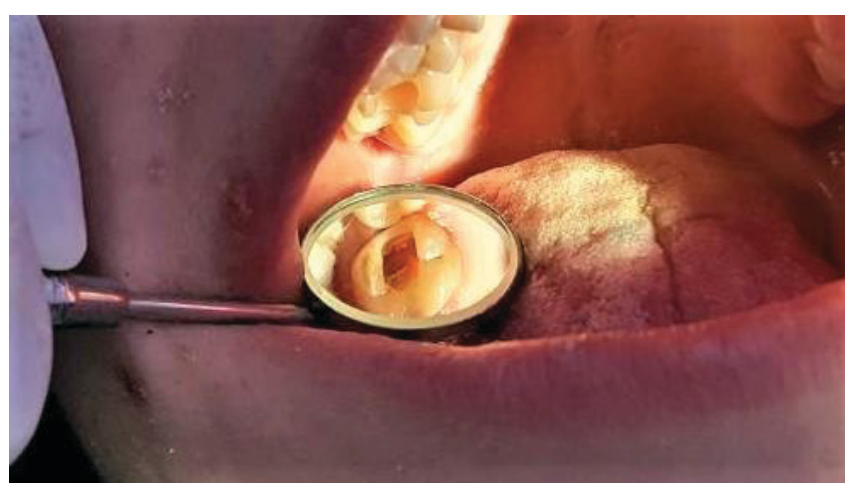

Figure 4. Reconstruction of the distal wall on tooth 16, thus transforming class II cavity in class I

Then the composite resin was inserted into the class I obtained cavity and light cured. The occlusal morphology has been easily restored. (Figure 5).

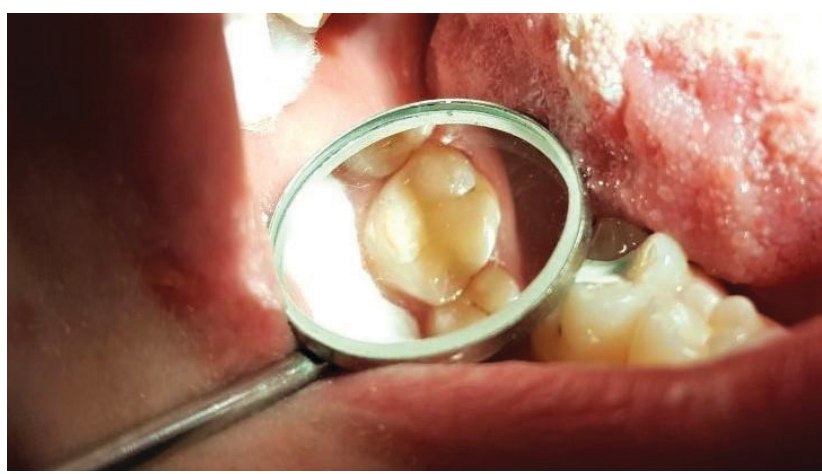

Figure 5. Final aspect of direct resin composite restoration, using centripetal technique, in tooth 16.

\section{Conclusions}

The major advantage of this technique is that it allows an accurate reproduction of contact point and contour, followed by an easy restoration of occlusal anatomy.

\section{Acknowledgements:}

For this article all the authors have equal contributions. 


\section{References:}

1. Popa MB. Estetica în Odontoterapia Restauratoare. București: Ed. Univ. „Carol Davila"; 2006.

2. Iliescu A, Gafar M. Cariologie și odontoterapie restauratoare. Editura Medicală: Editura Medicală; 2013.

3. Chandrasekhar V, Rudrapati L, Badami V, Tummala M. Incremental techniques in direct composite restoration. J Conserv Dent. 2017;20(6):386-91.

4. Demirci M, Tuncer S, Yuceokur AA. Prevalence of caries on individual tooth surfaces and its distribution by age and gender in university clinic patients. Eur $\mathrm{J}$ Dent. 2010;4(3):270-9.

5. Krämer N, Reinelt C, Frankenberger R. Tenyear Clinical Performance of Posterior Resin Composite Restorations. J Adhes Dent. 2015 Aug; 17(5):433-41.

6. Dumitriu H.T. Tratat de Parodontologie, Editura Viața Medicală Romanească, 2015, pg 49-50, 165, 171-172;

7. Nadig R, Bugalia A, Usha G, Karthik J, Rao R, Vedhavathi B. Effect of Four Different Placement Techniques on Marginal Microleakage in Class II Composite Restorations: An in vitro Study. . World Journal of Dentistry. 2011:2:111-6.
8. Romero MF, Haddock F, Todd M. Combination of centripetal and successive layering techniques for a stress-reduced posterior direct composite restoration. Gen Dent. 2017;65(3):72-6.

9. Tanaya K, Anita S, Karan B, Shalini A, Gurupriya K, Kunal K. Comparative evaluation of the bond strength of posterior composite with different cavity configurations and different liners using a two-step etch and rinse adhesive system: In vitro study. J Conserv Dent 2017;20(3):20(3): 166-9.

10. Bichacho N. The centripetal build-up for composite resin posterior restorations. Pract Periodontics Aesthet Dent. 1994;6(3):17-23; quiz 4.

11. Doozandeh M, Shafiei F, Mohammadi F. Microleakage of Class II composite resin restorations with self-adhesive composite resin liners. Gen Dent. 2017;65(4):41-7.

12. Fabianelli A, Sgarra A, Goracci C, Cantoro A, Pollington S, Ferrari M. Microleakage in class II restorations: open vs closed centripetal build-up technique. Oper Dent. 2010;35(3):308-13. 